\title{
Capital de risco: oportunidade de financiamento para as empresas de base tecnológica
}

\author{
Heloise das Neves Balan* \\ Nathalie Aparecida dos Santos Rôas**
}

RESUMO - O presente trabalho tem como principal objetivo analisar o capital de risco como uma fonte alternativa de financiamento para as empresas de base tecnológica. Para isso foi elaborado um questionário, procurando identificar a importância da inovação para as empresas de base tecnológica de Maringá e os principais empecilhos ao processo de inovação e captação de recursos pelas empresas. Através da metodologia aplicada constatou-se que as empresas pesquisadas possuem dificuldades na obtenção de recursos para o desenvolvimento de inovações. Conclui-se que a captação de recursos financeiros no país é de difícil acesso e o capital de risco é quase inexistente, o que acaba dificultando a obtenção de recursos pelas micro e pequenas empresas.

Palavras-chave: Capital de Risco. Incubadora de Empresas. Empresas de Base Tecnológica.

\section{INTRODUÇÃO}

Muitas empresas entram em falência antes mesmo de completar um ano de existência, principalmente devido à falta de preparo dos empresários no enfrentamento das inúmeras dificuldades inerente a um ramo desconhecido. Esses, em geral, não fazem nenhum estudo sobre o mercado que irão atuar, sobre os investimentos necessários para o estabelecimento do negócio e até mesmo sobre as linhas de crédito disponíveis.

Com a abertura dos mercados e o processo de globalização, as dificuldades enfrentadas pelas empresas aumentam devido ao acirramento da concorrência, a dinâmica das inovações e a interligação dos mercados mundiais. Diante deste cenário, as empresas entram em uma corrida contra o tempo para vencer a concorrência, minimizar custos, inovar, buscar mercado. Esta é uma corrida pela própria sobrevivência. Essa tendência mundial tem se consolidado e conseqüentemente trouxe consigo as dificuldades advindas da concorrência. Dificuldades estas que correspondem principalmente a questões mercadológicas e financeiras.

Para amenizar os problemas enfrentados pelas empresas e, para que estas possam competir em nível de igualdade com os produtos importados, desenvolveu-se uma nova forma de organização entre as empresas, denominada Arranjos Produtivos Locais (APL's). No caso das

\footnotetext{
*Economista pela Universidade Estadual de Maringá em 2007. Endereço eletrônico: heloisebalan@hotmail.com

** Economista pela Universidade Estadual de Maringá em 2007. Endereço eletrônico: nathalieroas@hotmail.com
} 
empresas de base tecnológica esta nova organização é denominada Incubadora de empresas. Dessa forma, vários empreendimentos são viabilizados, gerando inovações, emprego e renda.

As Incubadoras surgiram no Brasil em 1980, com a proposta de dar suporte aos empreendimentos no período de concepção de seus negócios, possibilitando melhores condições para a consolidação dos mesmos. Contudo, o apoio oferecido pelas Incubadoras, não ameniza totalmente as dificuldades enfrentadas pelas empresas nascentes, visto que muitos empreendimentos não conseguem sair da fase de incubação. Devido a isto quando as empresas são graduadas, passando a não mais contar com o apoio da Incubadora, elas têm que buscar linhas de financiamentos ou possíveis investidores para poder dar continuidade as suas atividades e ampliar seu negócio, em função da estrutura de mercado em que se encontram.

Para tentar solucionar os problemas enfrentados pelas empresas de base tecnológica, existem algumas formas de captação de recursos, entre elas o capital de risco. O qual não exige garantias, dependendo apenas do crescimento e lucratividade das empresas, ao contrário do financiamento tradicional.

Assim, este trabalho tem por objetivo verificar a possibilidade do capital de risco ser um meio de financiamento para as empresas de base tecnológica de Maringá, uma vez que são elevadas as dificuldades na obtenção de financiamentos tradicionais.

Além desta introdução, o presente o artigo esta composto por mais quatro seções. A primeira descreve a metodologia utilizada no trabalho, a segunda traz as definições de incubadoras de empresas, linhas de financiamento disponíveis para os empreendimentos de base tecnológica, capital de risco a terceira descreve e analisa os resultados obtidos pela pesquisa e, por fim, a última seções apresenta as considerações finais do trabalho.

\section{METODOLOGIA}

Para alcançar os objetivos propostos, foi realizada uma revisão de literatura baseada em artigos, livros e outras fontes de pesquisa para melhor definição do que vem a ser: incubadoras de empresas, empreendimentos de base tecnológica e capital de risco. Foi realizado também um estudo para verificar as linhas de financiamentos disponíveis para os empreendimentos e os possíveis investidores para essas empresas.

Posteriormente foi elaborado um questionário para caracterizar as empresas residentes na Incubadora Tecnológica de Maringá. A pesquisa foi elaborada para as 11 empresas residentes na Incubadora tecnológica de Maringá, dentre as quais 7 empresas colaboraram para os resultados

66

Economia \& Tecnologia - Ano 04, Vol. 12 - Jan./Março de 2008 
obtidos. Considerando que representam $64 \%$, pode-se concluir que é uma boa amostra para análise de dados.

\section{DEFINIÇÕES}

\subsection{INCUBADORA DE EMPRESAS}

As incubadoras de empresas surgiram na metade do século XX nos Estados Unidos, na região do Vale do Silício, expandindo-se para outros países. Em 1982, foi instalada a primeira incubadora de empresas do Brasil, localizada na cidade de São Carlos - SP. Com as incubadoras, vários empreendimentos foram viabilizados, gerando inovações, emprego e renda. De acordo com a ANPROTEC (2006), atualmente existem no Brasil cerca de 359 Incubadoras de Empresas onde estão instaladas mais de 2.000 empresas, além de serem responsáveis pela viabilização de cerca de 1.600 que são consideradas empresas graduadas, ou seja, estão em atividade no mercado.

Seu propósito é oferecer apoio para empreendimentos nascentes, dando suporte no período de concepção de seus negócios e possibilitando melhores condições para a consolidação dos mesmos, incentivando assim, principalmente a inovação. De acordo com Vedovello (2000), uma incubadora de empresas pode ser definida como um conjunto de empresas que compartilham um ambiente físico com instalações adequadas e infra-estrutura administrativa, proporcionando o nascimento, desenvolvimento e consolidação de novos negócios, além de propiciar o estabelecimento e fortalecimento de parcerias.

Esses empreendimentos, segundo Machado (2001), podem ser definidos como empresas comprometidas com o projeto, desenvolvimento e produção de novos processos, produtos ou serviços, onde a tecnologia é considerada inovadora, e caracterizada pela aplicação de conhecimento técnico-científico.

Os empreendimentos de base tecnológica demandam muitos recursos para se aprimorarem no mercado em que atuam, sendo esses recursos direcionados principalmente para atividades de inovação tecnológica. Para uma empresa de base tecnológica se manter no mercado é necessário um volume significativo de investimento para o seu fortalecimento, este muitas vezes é considerado como uma barreira, pois os recursos disponíveis para essa finalidade são escassos e sem eles o empreendedor fica impedido de prosperar no mercado. Os financiamentos direcionados ao desenvolvimento do produto são poucos, e quando existem são para empresas de maior porte e não para pequenas empresas.

Outra função das incubadoras, conforme Maculan (1996) é a de intermediar a relação das empresas com as agências de apoio a inovação. Santos (1987) afirma que as micro e pequenas 
empresas apresentam dificuldades para aquisição de equipamentos e possuem escassez de recursos financeiros para sua operação. Assim, dentre as vantagens oferecidas as empresas que se inserem nas incubadoras estão: informação sobre linhas de financiamento, apoio na elaboração dos seus projetos além do acesso de forma subsidiada à uma infra-estrutura adequada e serviços técnicoadministrativo para a realização de seus projetos, aproveitando o conhecimento científico e profissional dos empreendedores.

\subsection{DIFICULDADES NA OBTENÇÃO DE FINANCIAMENTO:}

A inserção tardia do Brasil no mercado mundial, entre outros fatores, faz com que a tecnologia desenvolvida no país fique aquém daquela desenvolvida por vários de seus concorrentes internacionais que estão a muito mais tempo no mercado. Por esse motivo a maioria dos empreendimentos de base tecnológica do país apresentam dificuldades quando comparadas com outros países. Outro problema com o qual as empresas de base tecnologia se deparam, refere-se ao fato dessas empresas atuarem, em geral, apenas em nichos de mercado, não desenvolvendo tecnologia "nova" para superar a concorrência dos outros países, mas apenas adaptando as tecnologias desenvolvidas para o mercado nacional.

$\mathrm{Na}$ maioria das empresas brasileiras, o capital destinado à P\&D de novos produtos, é muito inferior quando comparadas ao de outros países, que tem políticas claras de fundos de capital de risco, linhas de financiamento específicas para EBT`s ${ }^{7}$ e alguns incentivos fiscais. O Brasil oferece alguns programas nessa esfera, porém os recursos são escassos e as licitações são muito complicadas, diante da estrutura precária das empresas que os solicitam, além de possuírem sistemas gerenciais deficientes. Como conseqüência, não passam sequer da avaliação inicial. Storey e Tether (1998, p.1046) afirmam que "os instrumentos de apoio financeiro disponíveis no Brasil estão sempre voltados a empresas já constituídas, requerendo, em graus variados, um certo nível de consolidação de suas atividades"

Lemos (1998) destacou em sua pesquisa que 75\% das empresas incubadas apresentavam dificuldades de financiamento e $86 \%$ destas consideravam que as incubadoras contribuíam para a superação das dificuldades de financiamento por serem intermediárias entre as empresas e as instituições governamentais. Neste trabalho, destacam-se também itens como "falta de pessoal qualificado", "falta de infra-estrutura", "falta de recursos para treinamento" e "dificuldades em estabelecer parcerias para o desenvolvimento de tecnologias". (ibid, p.357).

\footnotetext{
${ }^{7}$ Empreendimentos de Base Tecnológica.
}

68 
De acordo com a pesquisa feita por (PINHO, CÔRTES, FERNANDES, 2002 apud TORKOMIAN, 1992), os principais problemas encontrados em EBT"s se referem "a escassez de capital, precariedade do marketing, instabilidade macroeconômica e a falta de capacitação gerencial". Portanto, o problema financeiro é a principal barreira às EBT's, visto que para a empresa se desenvolver e se adequar à competência gerencial, ela precisa necessariamente de capital para investir em novas fontes de P\&D.

Os recursos oferecidos pela maioria das instituições de fomento são para empresas de grande porte que possuam economias de escala, não restando muita alternativa para os pequenos empreendimentos a não ser sua capacidade empreendedora e inovadora, pois são atividades que se dedicam à introdução de novas tecnologias, que muitas vezes não foram testadas no mercado, caracterizando investimento de alto risco.

Nos Estados Unidos, investimentos desse porte são considerados venture capital, ou capital de risco, muito comum também em países da União Européia, mas no Brasil, esta atividade ainda esta bem no início, não apresentando ainda resultados muito significativos. Mesmo apresentando resultados ainda insatisfatórios, o capital de risco é uma alternativa para as pequenas empresas residentes em incubadoras que não podem contar com financiamento de suas atividades, por serem empresas de base tecnológica e a maioria ser de empreendedores universitários, os quais não possuem a quantidade necessária de ativos reais como contra garantia dos empréstimos (GONÇALVES, 2002).

\subsection{CAPITAL DE RISCO}

O venture capital, ou capital de risco é uma forma de capitalização onde um investidor coloca o seu dinheiro comprando uma participação acionária na empresa, que em geral é minoritária. Os investidores individuais que colocam o seu dinheiro nos estágios iniciais de crescimento da empresa são chamados de investidores anjo. No entanto, a forma mais comum de capital de risco é o fundo de investimento, geridos por administradores profissionais de forma a diluir os riscos de investimentos. (COSTA, 2005)

O capital de risco surgiu primeiramente nos Estados Unidos após a Segunda Guerra Mundial, auxiliando no incremento da economia americana. Desde o seu início, essa nova fonte de investimento teve grande repercussão nesse país, ajudando a desenvolver algumas das maiores empresas do mundo que atuam no ramo de tecnologia, como a Apple Computers Inc., a Intel, a HP e o Google, pois, de acordo com Bygrave e Timmons (1992), o capital de risco influenciou 
substancialmente a transformação de áreas como Boston e Vale do Silício em economias de alta tecnologia.

Com isso, o venture capital expandiu-se rapidamente para países da Europa, ajudando no desenvolvendo de sua indústria local, uma vez que este setor é fundamental para o discernimento da inovação no mundo inteiro. No Brasil, essa nova fonte de "financiamento" das empresas chegou apenas no início da década de 1990, repercutindo em "ações de diversas instituições no apoio ao empreendedorismo, à criação de incubadoras e à criação de mecanismos de financiamento adequados às diversas fases de crescimento das empresas”. (PAVANI, 2003, p.21)

Como as pequenas empresas de base tecnológica apresentam dificuldades para obtenção de financiamentos tradicionais disponibilizados pelas instituições financeiras, pelo fator de risco que as cercam, não restam muitas alternativas. Por isso o capital de risco é importante, porque entra financiando atividades que necessitam de altos investimentos em $\mathrm{P} \& \mathrm{D}$, principalmente as que atuam no ramo de tecnologia. O capital de risco tem como lógica a aceitação de um elevado risco no presente em troca de expectativas de alta rentabilidade no futuro, compatível com o risco assumido, constituindo-se um investimento de longo prazo com maturação superior a cinco anos (SOLEDADE et al., 1996). Ou seja, o retorno para os investidores depende do crescimento e do lucro gerado por essas empresas.

De acordo com Pavani (2003), capital de risco é composto por empresas juridicamente constituídas com a finalidade de realizar investimentos. Pode assumir a forma de bolding ${ }^{8}$, empresa de participações ou fundo de capital de risco. Em 1994 foi criada no Brasil a figura jurídica do Fundo Mútuo de Empresas Emergentes, que buscam operações em negócios de menor porte e modelos de negócios não testados, com alto potencial de retorno, mas com altos riscos associados.

Gorgulho (1996) apresenta a atividade capital de risco sob algumas formas organizacionais:

a) Fundos de Capital de Risco - Um fundo é gerido por uma empresa administradora e seus sócios são investidores de longo prazo. O administrador pode ser independente ou ligado a uma instituição financeira.

b) Subsidiárias corporativas - A atividade de capital de risco é exercida por uma subsidiária corporativa de uma instituição financeira ou de uma grande empresa, e os recursos do fundo são provenientes do caixa destas instituições.

\footnotetext{
${ }^{8}$ É um grupo que controla um conjunto de empresas por meio da compra da maior parte de suas ações. A holding não produz, ela apenas administra, já que é a majoritária. A formação de holding é considerada o estágio mais avançado do capitalismo. (MARQUES)
}

70 
c) Holdings independentes - Atuam como fundo, mas seu formato jurídico é o de uma holding. Este tipo de fundo é bastante comum no mercado brasileiro. A forma de constituição é a de uma empresa fora do país, em geral em paraíso fiscal, a integralização do capital é realizada fora, e o dinheiro entra no país sob a rubrica capital estrangeiro.

De acordo com Viégas (2007, p.27) “a indústria de capital de risco” brasileira “ainda tem um longo caminho até chegar aos patamares de países como Suécia, Israel, Grã-Bretanha, Coréia do Sul e Estados Unidos, onde os investimentos superam 1\% do PIB”. No Brasil, este percentual é inferior a $0,1 \%$.

Contudo, o país ainda esta distante de se tornar auto-suficiente nessa modalidade, pois o cenário atual decorre da falta de incentivos, tanto por parte do governo, quanto da iniciativa privada, além da necessidade de investimento na educação para fortalecer o desenvolvimento de tecnologias competitivas.

\section{DISCRIMINAÇÃO E ANÁLISE DOS DADOS}

Para compreender melhor a situação de micro empresas inseridas nas Incubadoras, foi elaborado um questionário sobre o processo de inovação das empresas de pequeno porte para detectar quais são as principais soluções e problemas enfrentados pelas empresas de base tecnológica.

Em relação à importância da inovação no interior das empresas, a maioria afirmou ser muito importante, sendo a inovação classificada como alta e imprescindível, como pode ser observado pela gráfico 01 .

GRÁFICO 1 - IMPORTÂNCIA DA INOVAÇÃO PARA AS EMPRESAS

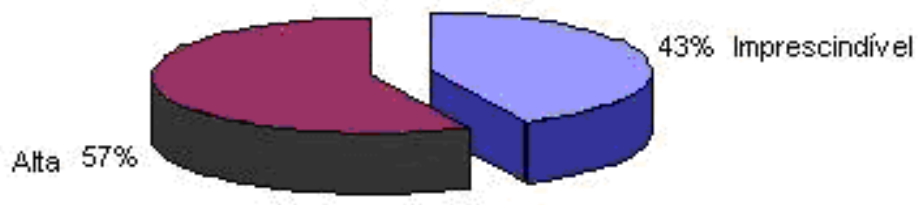

FONTE: Elaboração Própria

Em outra questão, foram verificados os principais empecilhos ao processo de inovação, em que cada empresa assinalou até quatro respostas. Conforme a tabela 1 abaixo, o principal empecilho para a inovação é a falta de recursos financeiros, seguido pela falta de equipamentos, desconhecimento de instrumentos de incentivos e recursos públicos destinados à inovação e a burocracia existente, os quais, de uma maneira geral, estão relacionados à escassez de recursos. 
TABELA 1 - PRINCIPAIS EMPECILHOS AO PROCESSO DE INOVAÇÃO DA EMPRESA (\%)

\begin{tabular}{lc}
\hline \multicolumn{1}{c}{ Empecilhos } & Percentual \\
\hline Falta de pessoal & 5 \\
Falta de Tempo & 5 \\
Falta de recursos financeiros & 25 \\
falta de equipamentos & 11 \\
Falta de apoio de parceiros tecnológicos & 11 \\
Desconhecimento de instrumentos de incentivo à inovação & 16 \\
Burocracia para o uso de incentivos públicos & 16 \\
\hline
\end{tabular}

FONTE: Elaboração Própria

A mesma pesquisa constatou-se que $57 \%$ das empresas desconhecem os atuais incentivos governamentais e programas das agências de fomento e subsídios à inovação, o que torna mais difícil para essas empresas o acesso a financiamentos destinados a inovação.

Em pergunta sobre a importância do registro de patentes no seu processo de inovação, $43 \%$ das empresas afirmaram ser alta e $29 \%$ ser imprescindível para o desenvolvimento de seus negócios. Portanto pode-se observar que o processo de inovação é de extrema importância para as empresas de base tecnológica, porém o incentivo financeiro ainda é escasso.

\section{CONSIDERAÇÕES FINAIS}

No Brasil, a cultura de capital de risco ainda deixa muito a desejar, pois o país teve seu processo de industrialização atrasado quando comparado a outros países. Porém, o capital de risco tem muito a crescer, pois o desenvolvimento de empresas inovadoras esta aumentando a cada dia, demandando incentivos para a sua expansão.

Diante das informações expostas acima, pode-se perceber que a Incubadora Tecnológica de Maringá tem grande potencial para atrair investidores, visto que as empresas estão preocupadas com a inovação, necessitando apenas de incentivos para dar continuidade aos seus projetos.

Dessa forma as empresas receptoras desses recursos melhorariam a tecnologia utilizada, reduzindo o seu custo de produção, e gerando mais emprego e renda para a sociedade local, o que consequentemente se transformaria em um retorno para os seus investidores. 


\section{REFERÊNCIAS}

BYGRAVE, W. D. e TIMMONS, J.A. Venture Capital at the Crossroads. $1^{\circ}$ edição. Boston, Massachusets: Harvard Business School Press, 1992.

COSTA, E. Financiando a inovação nas empresas (e inovando nas formas de financiamento). Parcerias Estratégicas, $\mathrm{n}^{\circ}$ 20. Junho/2005.

GONÇALVES, E. Financiamento de Empresas de Base Tecnológica: algumas evidências da experiência brasileira. Revista Econômica do Nordeste, Fortaleza, v.33, n 1, jan. - mar. 2002.

GORGULHO, L. F. O capital de risco como alternativa de financiamento às Pequenas e Médias empresas de base tecnológica: $O$ caso Contec/BNDES. Dissertação de Mestrado, Instituto de Economia Industrial/UFRJ. Rio de Janeiro, 1996.

LEMOS, M. V. As Incubadoras e o apoio às pequenas empresas de base tecnológica para superação de suas dificuldades. IN: SEMINÁRIO NACIONAL DE PARQUES TECNOLÓGICOS E INCUBADORAS DE EMPRESAS, 8., Belo Horizonte, 1998. Anais: Belo Horizonte: ANPROTEC, 1998a. p. 351-362.

MACULAN, A. M. D. As pequenas empresas de base tecnológica. Rio de Janeiro: COPPE, 1996.

MARQUES, C. Os três tipos de fusões de empresas no Brasil. www.imesexplica.com.br. Acesso em: dezembro, 2007.

PAVANI, C. O Capital de Risco no Brasil. Rio de Janeiro: E-pappers Serviços Editoriais Ltda, 2003.

SANTOS, S. A. Criação de empresas de alta tecnologia, capital de risco e os bancos de desenvolvimento. São Paulo: Pioneira,1987.

SOLEDADE, D. et al. Fundo de empresas emergentes: novas perspectivas de capitalização para pequenas e médias empresas. Revista BNDES, no.6, p. 23-36, dezembro 1996

STOREY, D. J. e TETHER, B. S. Public policy measures to support new technologybased firms in the Europe Union. Research Policy, no 26, p. 1037-1057, 1998.

TORKOMIAN, A. L. Estrutura de Pólos Tecnológicos: um estudo de caso. Dissertação de mestrado, São Paulo: FEA - USP, 1992.

VEDOVELLO, C. Aspectos relevantes de parques tecnológicos e incubadoras de empresas. Revista do BNDES. Rio de Janeiro, v. 7. n. 14, p. 273-300, dez. 2000.

VIÉGAS, F. Anjos Inovadores. Belo Horizonte, Revista Update, p. 27, Janeiro 2007. 
